\title{
The active evolutionary lives of echinoderm larvae
}

\author{
RA Raff ${ }^{1}$ and M Byrne ${ }^{2}$ \\ ${ }^{1}$ Department of Biology and Indiana Molecular Biology Institute, Indiana University, 150 Myers Hall, 915 E. Third St, Bloomington, \\ IN 47401, USA; ${ }^{2}$ Department of Anatomy and Histology, F-13, University of Sydney, Sydney, NSW 2006, Australia
}

\begin{abstract}
Echinoderms represent a researchable subset of a dynamic larval evolutionary cosmos. Evolution of echinoderm larvae has taken place over widely varying time scales from the origins of larvae of living classes in the early Palaeozoic, approximately 500 million years ago, to recent, rapid and large-scale changes that have occurred within living genera within a span of less than a million years to a few million years. It is these recent evolutionary events that offer a window into processes of larval evolution operating at a micro-evolutionary level of evolution of discrete develop-
\end{abstract}

mental mechanisms. We review the evolution of the diverse larval forms of living echinoderms to outline the origins of echinoderm larval forms, their diversity among living echinoderms, molecular clocks and rates of larval evolution, and finally current studies on the roles of developmental regulatory mechanisms in the rapid and radical evolutionary changes observed between closely related congeneric species.

Heredity (2006) 97, 244-252. doi:10.1038/sj.hdy.6800866; published online 19 July 2006

Keywords: larval evolution; evolutionary developmental biology; echinoderms; regulatory genes; macroevolution

\section{Origins of echinoderm larvae}

The diversity of larval forms in marine invertebrates has long fuelled discussion on evolutionary origins of novel features and pathways of evolutionary change. Most phyla of animals are marine, and most of these animals, annelids, molluscs, echinoderms, hemichordates, brachiopods, phoronids, sipunculans, ascidians and others are benthic as adults, but have planktonic so called 'primary' larvae with different body plans than possessed by the adults. These larvae are free-swimming and generally feeding forms that provide a tremendous dispersibility to the largely sedentary adults. The term 'primary' larva refers to the idea that these larval forms evolved early in the histories of the marine phyla, and in fact may represent the most ancient metazoans prior to the invention of the benthic habit (Jagersten, 1972). The term 'secondary' larvae is used to refer to larvae such as the tadpoles of frogs or the larvae of holometabolous insects that share the basic body plan of the adults and were clearly evolved following the evolution of the adult body plan. We will not use this terminology because it reflects an outdated view derived from the 19th Century recapitulationist ideas of Haeckel applied literally to larval development.

A mapping of developmental mode onto phylogenetic trees of metazoan phyla indicates that nonfeeding direct developing embryos were basal, with indirect development arising later in some clades (Figure 1) (Sly et al, 2002, 2003). Indirect developing 'planktotrophic' larvae likely arose independently in lophotrochozoan and hemichordate + echinoderm clades as part of the Cam-

Correspondence: RA Raff, Department of Biology and Indiana Molecular Biology Institute, Indiana University, 150 Myers Hall, 915 E. Third St, Bloomington, IN 47401, USA. E-mail: rraff@bio.indiana.edu

Received 26 January 2006; accepted 5 June 2006; published online 19 July 2006 brian radiation over half a billion years ago. There is evidence from gene expression patterns in deuterostome and protostomes larvae that the Bilateria may share developmental features and gene expression patterns (Arendt et al, 2001). Arendt et al (2001) postulated that bilaterian ancestors developed through a primary ciliary feeding larva, but their observations are also consistent with the co-option of gene systems into early development that were subsequently incorporated into planktotrophic larvae.

Planktotrophic larvae only become possible once animals attain a sufficient body size allowing spawning of large numbers of gametes, the 'energetic hypothesis' (Chia, 1974; Olive, 1985). Large animal body sizes appear in the fossil record in the latest Precambrian, and but became prevalent in the Cambrian radiation. The presence of metazoan embryos (with diameters similar to living direct developing forms) present in late Precambrian rocks is well supported (Xiao et al, 1998; Raff et al, 2006). The fossil record also is consistent with the evolution of planktotrophic larvae in the late Cambrian and early Ordovician (Peterson, 2005).

Echinoderms share a common dipleurula larva with hemichordates. Although discussions on potential 'indirect vs direct developing' ancestral states continues for some taxa (Haszprunar et al, 1995; McHugh and Rouse, 1998), for modern Echinodermata, the feeding, planktotrophic larva is well supported as a plesiomorphic character (Strathmann, 1978; Raff, 1992, 1996; Wray, 1996; Smith, 1997; McEdward and Miner, 2001; but see Mooi and David, 1998). Thus, the evolutionary origins of echinoderm planktotrophic larvae lie in the distant past. However, the study of the larval forms of living echinoderms indicates that a great deal of larval evolution has taken place in the recent past and continues dynamically among closely related living clades. 


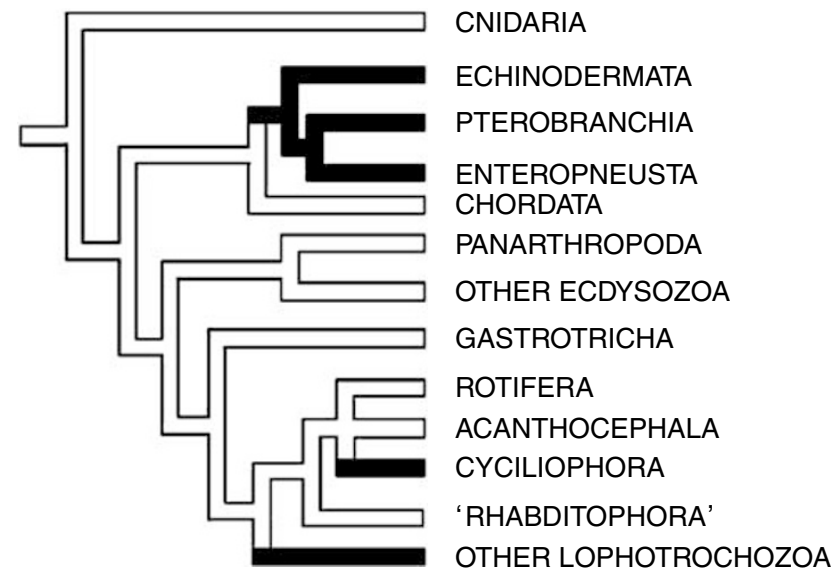

Figure 1 An 18S rDNA consensus metazoan phylogenetic tree with developmental modes mapped. Indirect development present (black branches), direct development present (white branches). Not all phyla shown, and some major super phylum clades are bundled, eg Ecdysozoa, Lophotrochozoa. The tree is consistent with direct development as basal, and indirect-developing larvae arising independently in at least three clades. From Sly et al (2003).

Indirect larval development considered from a developmental perspective seems most likely to have arisen by the intercalation of gene sets already used in the ancestral direct-developing adult to generate new features in early development (Valentine and Collins, 2000; Sly et al, 2002, 2003). Thus, features such as ciliary bands and larval guts would have arisen as the results of cooption of already existing genes and gene expression modules into an earlier time in development. Eventually, a distinct larval phase of life history would have evolved, followed by the evolution of imaginal cells and metamorphosis (Figure 2). The result was the appearance of planktonic feeding larval forms distinct in developmental processes, anatomy and ecological adaptations from the benthic adults.

It is this radiation that produced the ancestors of the planktotrophic larvae of living crown group echinoderm clades; larval forms continue to evolve, and not all living echinoderms have indirect-developing planktotrophic larvae. The interesting fact is that these other living larval forms are the modified descendents of planktotrophic larvae in their respective clades. In a number of examples, non-feeding larvae with rudimentary features of feeding larvae indicate the evolutionary transition. These are the subjects of the current studies summarized in this review.

\section{Echinoderm living larval diversity}

Echinoderm embryos undergo complete radial cleavage and undergo gastrulation by invagination. These gastrulae develop into a bilaterally symmetrical larva, the structure of which differs in each echinoderm class, and within classes dependent on egg size. Echinoderms that have small eggs develop through free-swimming planktotrophic (feeding on plankton) larvae (Figure 3). These larvae are transparent and so internal development is readily followed. The archenteron grows forward to connect with the mouth while the blastopore remains as the anus. Planktotrophic echinoderm larvae have an intricate array of ciliary bands that they use for feeding

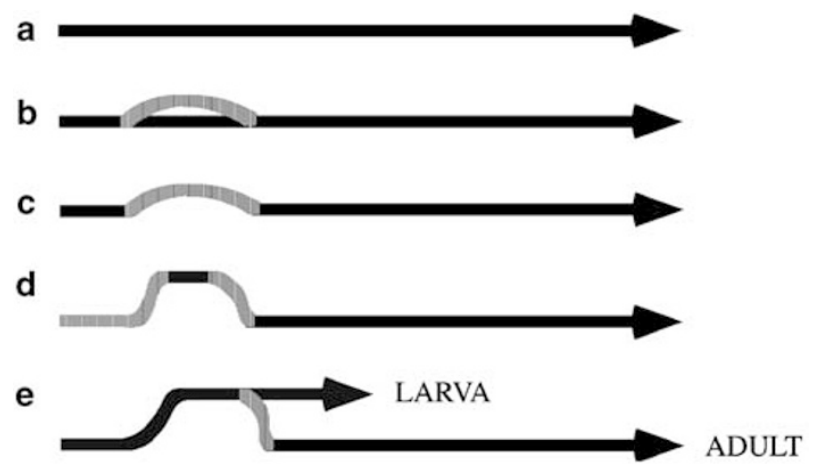

Figure 2 Evolutionary interpolation of larval features into an ancestral direct-developing ontogeny. (a) The arrow represents the course of direct development of an ancestral bilaterian. There is no larva. Adult features appear progressively with growth and allometric changes in proportions. Developmental regulation includes genes and processes characteristic of adult development in living bilaterians, eg Hox genes in body axis specification. (b) Interpolation of a facultative feature into early development (vertical dashes). Depending on conditions either path can be followed. (c) Later integration of facultative larval feature into a required larval feature. Development is largely direct, but some larval features are present (eg ciliary bands used for swimming). (d) Co-option of additional features to give rise to an integrated larval stage (solid bar in hatched pathway). A larval regulatory system distinct from the adult is arising. Most, but not all, adult features now arise from the remodeling of larval features. (e) A fully integrated biphasic ontogeny arises. Larval ontogeny is indicated by the upper arrow. Adult features (lower arrow) arise primarily from imaginal cells arising in the larva. Developmental regulatory controls have diverged into fully larval and adult components of development. From Sly et al, 2003.

and locomotion. Echinoderms that spawn large eggs develop through non-feeding larvae that lack a functional gut and which have a simple pattern of ciliation. Development of these larvae is supported by the nutritive reserves present in the egg (lecithotrophy). Most classes possess feeding as well as non-feeding clades, although all living crinoids have non-feeding development. Crinoids underwent a stringent bottleneck in the Permian extinction, and it is likely that survivors descended from a clade that had lost feeding larvae. The feeding larvae of Paleozoic crinoids are unknown in the fossil record.

Echinoderm feeding larvae (Figure 3) include dipleurula type (holothuroid auricularia (sea cucumbers); asteroid bipinnaria (starfish)) and pluteus type (ophiuroid ophiopluteus (brittle stars); echinoid echinopluteus (sea urchin)) larvae. The similarity of echinoderm dipleurula larvae and the hemichordate tornaria has long been used as evidence to suggest that this larval type is the basal form for the Deuterostomia (Garstang, 1894; Nielsen, 1995; Tagawa et al, 2001), although convergence has also been argued (Nezlin and Yushin, 2004). Significantly, the recent finding of a crinoid larva with a single dipleurula-like ciliary band provides further evidence that the dipleurula form is basal (Nakano et al, 2003). The similarity of echinoplutei and ophioplutei was taken to suggest a close relationship between echinoids and ophiuroids, but mitochondrial DNA phylogenetic analyses show this is not the case, with brittle stars more closely related to starfish than to sea urchins (Smith, 1997). The similarity of these larvae is a striking example of parallel evolution. 

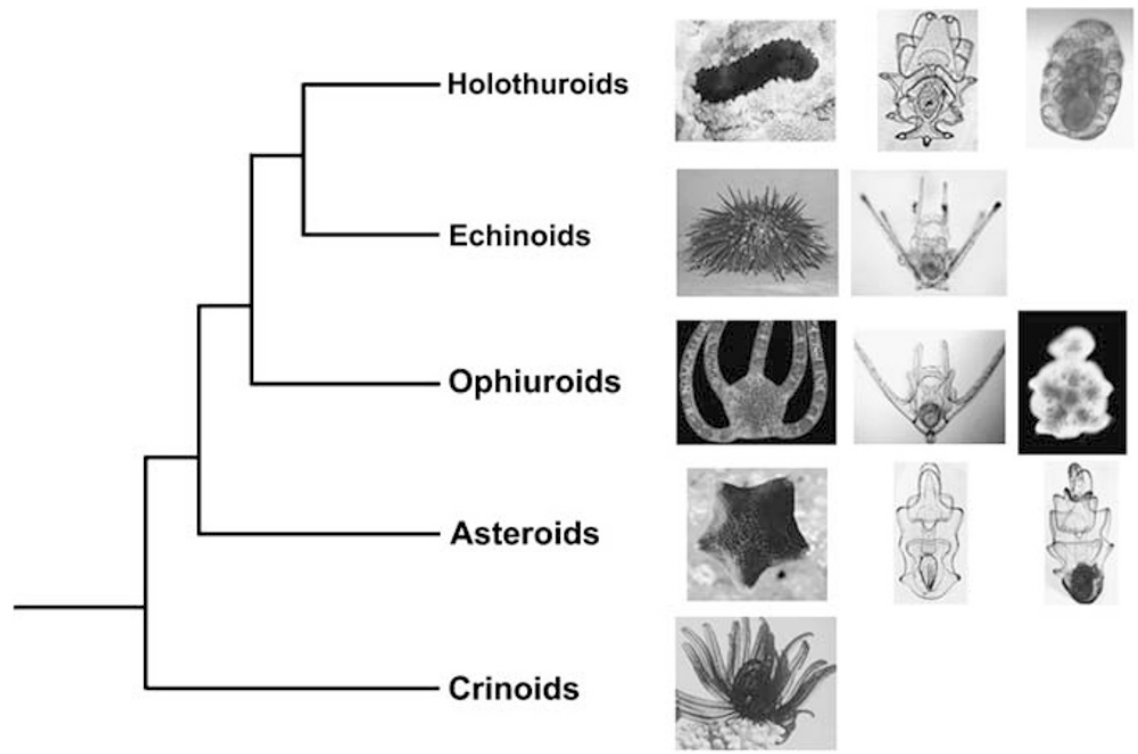

Figure 3 Phylogenetic relationships of the echinoderm classes (After Janies, 2001) showing the adults and planktotrophic larvae. Right three rows of figs show representative adults, feeding larvae, and pre-metamorphic larvae. Crinoids do not have a feeding larva. Holothuroids, asteroids and ophiuroids have two larval stages and early larva (auricularia, bipinnaria and ophiopluteus, respectively) and late metamorphic settlement stage larva (doliolaria, brachiolaria and vitellaria, respectively). Echinoids have one larval stage, the echinopluteus, which is also the settlement stage.

The holothuroid auricularia has one ciliary band that loops around the body with a topology identical to that of the ciliary band in the tornaria. Late in development the auricularia gives rise to the metamorphic stage larva, the doliolaria larva by reorganisation of the ciliary band into transverse rings. The doliolaria does not feed, and slowly transforms into the juvenile sea cucumber. Sea cucumbers with direct development lack the auricularia. The gastrula develops directly into the doliolaria. The lack of a distinct metamorphosis in sea cucumbers and the confluence of larval and adult body plans in these sea cucumbers suggest a paedomorphic condition (Semon, 1888; Mooi and David, 1998).

Asteroids have the bipinnaria larvae that has two ciliary bands that loop around the body. In some species the bipinnaria develops into the metamorphic stage larva, the brachiolaria with development of the brachiolar apparatus at the anterior end. This structure includes three sticky arms (brachia) and an adhesive disc used for benthic attachment. Starfish with non-feeding development lack a bipinnaria and the gastrula gives rise directly to a brachiolaria. The morphology of the brachiolaria differs depending on where development occurs (plankton or benthos) (Figure 4).

Echinoids (sea urchins) and ophiuroids (brittle stars) have pluteus-type larvae with a ciliary band that follows the contour of the larval arms. Echinoplutei have up to six pairs of arms and ophioplutei have up to four pairs of arms. Each arm is supported by a calcitic skeletal rod. In some ophiuroids the ophiopluteus develops into the metamorphic stage larva, the vitellaria, which has transverse ciliary bands. Ophiuroids with non-feeding development have reduced plutei or a vitellariae. Echinoids do have a distinct metamorphic stage larva. Echinoids with lecithotrophic development may have a reduced pluteus or have a simple spherical larva with no pluteus structures. The presence of reduced or vestigial pluteus features in the non-feeding larvae of several ophiuroid and echinoid species provides a link to an ancestral-form that had a feeding pluteus.

Evolution of non-feeding developmental modes from feeding larval ancestors is common, with conservatively at least seven such occurrences among six living orders of sea urchins, and four or more times just within a small group of asterinid starfish (Wray, 1996; Hart et al, 1997). The events produce dramatic changes in larval life history, development, and morphology (Figure 4). Changes in larval forms has occurred rapidly in echinoids and asteroids, and there is considerable convergence in these events (Wray, 1996; Jeffery and Emlet, 2003; Raff et al, 2003; Zigler et al, 2003; Byrne, 2006).

\section{Molecular clocks and larval evolution}

Surprisingly, it has been possible to explore the evolution of direct-developing larvae in extinct clades of sea urchins, including methods pioneered by Emlet (Jeffery and Emlet, 2003). These methods involve analysis of adult characters, including larger gonopore sizes, changed crystallographic axes of test plates, and in cases of brooders the presence of juveniles preserved among the adult's spines, or in marsupia in the test). In some rare circumstances these details are preserved in fossils. Where a good stratigraphic record is also available, rates of evolution can be estimated. Jeffery and Emlet (2003) have done this for Australian Tertiary temnopleurid sea urchins. The rates of speciation of direct-developing and brooding forms is high, and species durations have an average of $3 \mathrm{myr}$, indicating both high speciation and extinction rates.

The remarkable fossil preservation of sea urchins exploited by Jeffery and Emlet (2003) is not common. A fossil record of developmental mode is absent for most 

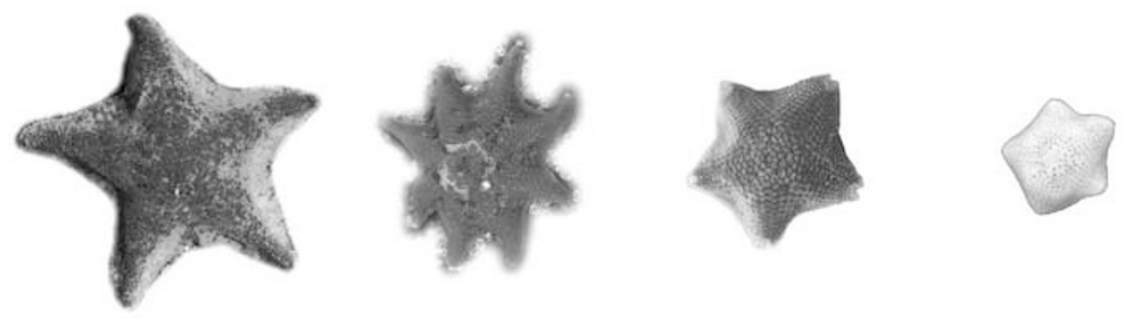

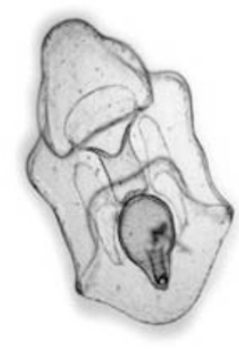

feeding, planktonic

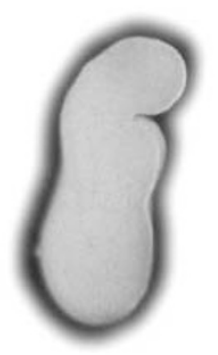

nonfeeding, planktonic

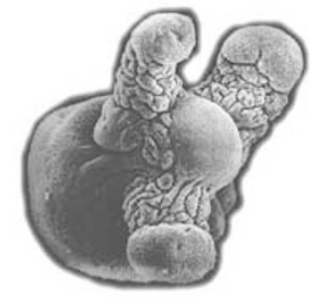

nonplanktonic, in egg masses

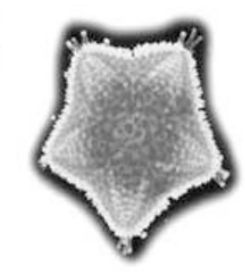

viviparous

Figure 4 Diversity of asterinid starfish adults and developmental stages. From right to left; Patiriella regularis, the largest species has a feeding larva; Meridiastra calcar has a planktonic non-feeding larva; Parvulastra exigua has a benthic non-feeding larva and Parvulastra vivipara the smallest species has intra-gonadal reduced larvae and gives birth to juveniles.

living echinoderms, and it has been impossible until recently to directly date larval evolutionary events. That has changed with the application of molecular clock methods. Ideally, such clocks should tie the rate of evolution of a set of mitochondrial or nuclear genes to well dated biogeographic events, as done by Lessios et al (2001; Zigler et al, 2003). Calibration has to be made to geological events, and clocks will be most accurate if not extrapolated far into the past because of increases in multiple substitutions at nucleotide sites. Application of clock times calibrated on the basis of timing of the closing of the Isthmus of Panama and the DNA sequences from sister species on both sides of it indicate that major changes in developmental mode from indirect feeding to non-feeding direct development took place within two living clades, about 4 mya in Heliocidaris erythrogramma (Zigler et al, 2003) and 4-7 mya in a second (Holopneustes) clade (Jeffery et al, 2003). Even more rapid rates of larval evolution are suggested for starfish in the developmentally diverse asterinids (Figures 4 and 5), in which large changes in developmental mode have taken place in less than 2 myr (Hart et al, 1997).

A final point is the revelation by the use of molecular phylogenies that demonstrate that gene trees differ from larval features trees (eg Hart et al, 1997; Byrne, 2006). These findings show dramatically that the features of direct-developing larvae are convergent in embryological and molecular features and have arisen independently with considerable frequency in asteroid and echinoid lineages (Emlet et al, 1987; Wray, 1996; Villinski et al, 2002; Raff et al, 2003; Hart et al, 2004).

\section{Comparative biology, diversity and molecular phylogeny}

Modern evolutionary developmental biology (evo-devo) has become enormously productive through the applica-

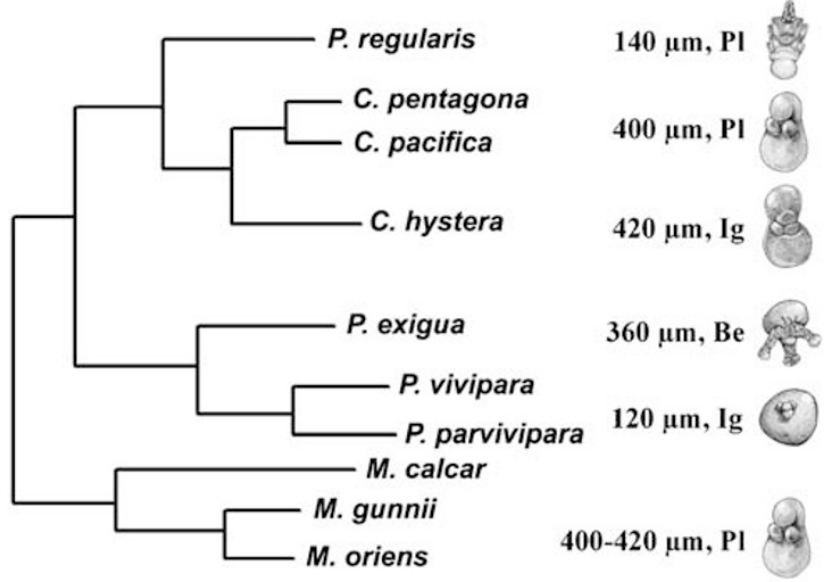

Figure 5 Phylogenetic relationships of asterinid sea stars (After Hart et al, 1997) showing egg diameter, location of development and larval form. Patiriella regularis has the ancestral-type ontogeny with a small egg and planktonic feeding larva. Species with planktonic non-feeding larvae evolved separately in the Meridiastra and Cryptasterina clades. Parvulastra exigua has a benthic 'tripod' larva. Evolution of intragonadal development in Parvulastra species from an exigua-like ancestor with a tripod larva occurred 1-3 Mya, based on COI sequence divergence (Hart et al, 1997). This resulted in a secondary reduction in egg size and development through a vestigial non-feeding larva that metamorphoses into a minute juvenile that cannibalizes its siblings before leaving the parent. Viviparity in Cryptasterina pacifica and C. hystera evolved from a C. pentagona-like ancestor that had a planktonic non-feeding larva. They have an unmodified larva that swims in the gonad. C. pacifica is estimated to have evolved as recent as 0.5 Mya (Hart et al, 1997). Be, benthic; Ig, intragonadal; Pl, planktonic.

tion of molecular phylogenetic and developmental genetic discoveries and tools to the older tradition of comparative tradition of evolutionary developmental biology (Raff and Love, 2004). Two taxa of echinoderms have been extensively studied using this expanded 
comparative approach. One is the asterinid starfish genus Patiriella and its close relatives in the Asterinidae, a major family of sea stars (Figure 4). Molecular phylogeny has provided a robust framework with which to assess pathways of developmental change (Byrne, 2006). Southern Australia has been a hot spot for radiation of asterinid sea stars and most of them are direct developers. Research has focussed on five genera (Patiriella Meridiastra, Aquilonastra, Parvulastra, Cryptasterina) each of which exhibits a number of life history mode and larval types (Figures 4 and 5). With the planktotrophic larva, the plesiomorphic character for these sea stars, the phylogeny indicates at least six independent origins of leicithotrophy (Figures 4 and 5). As a developmental module, the bipinnaria, has been completely deleted from the ontogeny of the lecithotrophs. Lecithotrophic brachiolaria have no traces of ciliary bands or the intricate bipinnaria nervous system (Byrne et al, 2001a).

The larval forms in the Asterinidae include the greatest diversity seen in the Echinodermata ranging from planktonic feeding and non-feeding larvae, strange looking benthic forms that maintain a tenacious hold on the sea floor and reduced forms that swim in the parent's gonads (Figure 4). Most clades contain species with at least two developmental modes (Figure 5). With numerous independent origins of lecithotrophy in the Asterinidae, it is not surprising that larval anatomy is variable. Planktonic brachiolaria have one large and two small brachia and these differ in shape in the different genera (Byrne, 2006). Benthic brachiolaria come in two varieties, the tripod larva with three arms equal in length (Parvulastra) and sole larva with a two lobed (Asterina) attachment structure. Intragonadal larvae also come in two varieties, vestigial intragonadal brachiolaria (Parvulastra) that may completely lack larval features to functional brachiolaria that look no different to their planktonic cousins (Cryptasterina).

There have been multiple transitions and pathways involved with the switch to different modes of lecithotrophic development in the Asterinidae. A striking example of different pathways is seen in evolution of the most derived life history mode seen in the echinoderms, live birth or viviparity. In Parvulastra viviparity evolved from an immediate ancestor that that a benthic tripod larva while in Cryptasterina this life history mode evolved from an immediate ancestor that had a planktonic larva (Hart et al, 1997). For the Asterinidae the rapid evolution of developmental features has resulted in a diverse suite of larval phenotypes within cryptic morphospecies complexes. Evolution of development has clearly been a driving force in the rapid speciation in these sea stars. Attention to ontogeny has uncovered previously unappreciated biological diversity and rapid convergent evolution of distinct larval forms.

No echinoids of comparable larval diversity to the asterinids are known. However, two congeneric species of Australian sea urchins, Heliocidaria tuberculata and $H$. erythrogramma, only 4 myr diverged, have offered an exceptional experimental system for the study of developmental mechanisms of larval evolution in two closely related species (Zigler et al, 2003). These two species have, respectively, a typical pluteus feeding larva and a direct-developing non-feeding larva (Figure 6). The $H$. erythrogramma larva arises from a large egg, and does not feed. H. erythrogramma has undergone profound changes in its maternal provisioning, a feature linked to evolution of development in echinoderms (Byrne et al, 1999; Villinski et al, 2002). The result is an egg with 100-fold the content of the egg of the indirect-developing $H$. tuberculata. The pluteus larva of indirect developers feed in order to build a sufficient mass to produce a juvenile sea urchin and undergo metamorphosis. H. erythrogram$m a$ has no need to feed to accomplish that end (Emlet and Hoegh-Guldberg, 1997). The $H$. erythrogramma larva is externally simple in shape and has no external arms, oral ectodermal features such as a mouth, and lacks a functioning gut. The truncation of development of larval features is accompanied by a vastly accelerated development of the adult sea urchin rudiment. $H$. erythrogramma possess remnant features that show its derivation form a pluteus larva (Emlet, 1995; Byrne et al, 2001b). The simplest interpretation of these two larval forms is that $H$. erythrogramma has through acquisition of a large egg gained the ability to develop through metamorphosis without feeding, with the subsequent loss of feeding larval features (Wray, 1996). However, it is clear that the simple scenario of loss of larval features is not sufficient, and that gains of novel features have been prevalent throughout the novel ontogeny of $H$. erythrogramma. Many of these may serve as models for understanding the changes to be expected in other clades.
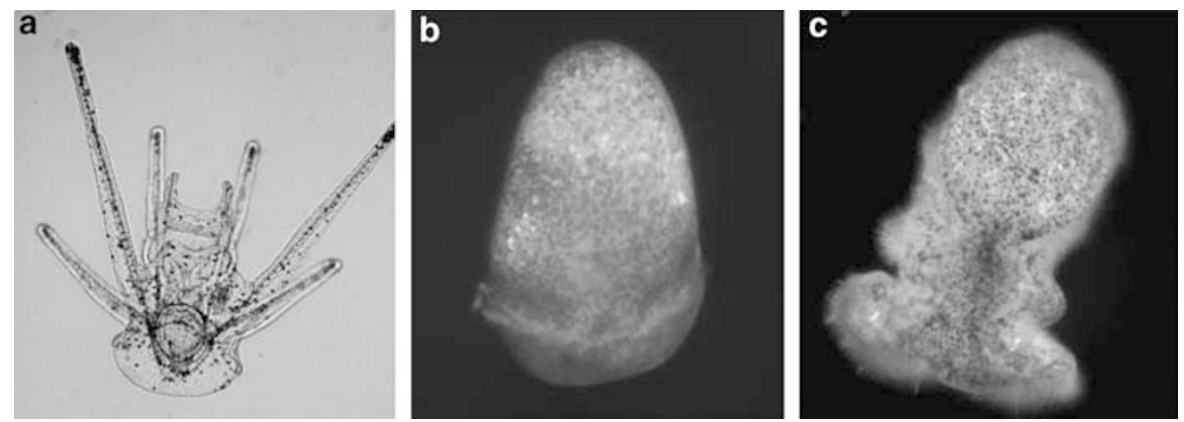

Figure 6 Larval diversity of the sea urchins in the genus Heliocidaris. (a) Pluteus of H. tuberculata. (b) Non-feeding, direct-developing larva of H. erythrogramma. These two specis diverged about 4 mya (Zigler et al, 2003). The abbreviated ciliary band is visible as a clear band on the lower part of the larva. Other pluteus features, arms and gut, are absent. (c) Hybrid larva from the H. erythrogramma x H. tuberculata cross. This is a dorsal view of a 2-day-old larva. Note the lobes that bear the ciliary band. Larval arms, mouth and gut will for by about four days of development. After Raff et al (1999). 


\section{Developmental-genetic approaches to echinoderm larval evolution}

Studies of evo-devo have until recently largely focussed on macro-evolutionary problems involving distant clades, such as in the relationship of animal body plans to Hox genes expression patterns (eg in the evolutionary reorganization of the snake body axis: Cohn and Tickle, 1999). Informative studies of developmental-genetic features of echinoderms at the macro-evolutionary scale have been made. Thus, although the substantial diversification in echinoderm planktotrophic larvae extends into the early Paleozoic, Hinman et al (2003) have made the remarkable observation that at least some portions of the gene networks that underlie larval development have been retained between starfish and sea urchins since the divergence of these two lineages. As echinoids produce a larval skeleton and starfish do not, their observation that a regulatory gene involved in skeletogenesis in the sea urchin is used differently in the starfish, in that it responds to endomesodermal inputs that do not affect it in the sea urchin embryo. This conservation is counterbalanced by important changes in deployment of major regulatory genes among echinoderm classes observed by Lowe and Wray (1997). Studies of homeobox genes involvement in the production of the pentameral adult and of patterning of the adult rudiment radial nervous system have begun to yield an understanding of how the bilaterian adult body plan has been modified in echinoderms, and how it arises in development (Arenas-Mena et al, 2000; Minsuk and Raff, 2002; Sly et al, 2003; Byrne et al, 2005; Cameron et al, 2006; Morris and Byrne, 2005).

It also has become possible to approach evo-devo phenomena operating on a more micro-evolutionary scale, such as in larval evolution among closely related species. The use of closely related species with divergent ontogenies to investigate evolutionary pathways is particularly powerful because homologous features can be compared. Among echinoderms, this approach is being with several asteroid and echinoid genera (Raff, 1992, 1996; Hart et al, 1997, 2003; Jeffery and Emlet, 2003; Jeffery et al, 2003; Raff et al, 2003; Love and Raff, 2006; Wilson et al, 2005a, b; Byrne, 2006). In the case of the echinoids, the study of developmental evolution rests on the great body of studies of the developmental biology of indirect-developing echinoids (see Davidson et al, 1998 for an introduction). We cite only some of the relevant studies here, but the reader should note the importance of studies of developmental mechanisms in indirectdeveloping echinoids.

In addition to provisioning discussed in the previous section, the maternal developmental information of $H$. erythrogramma has been substantially modified. Wray and Raff $(1989,1990)$ showed that the cell fate map was highly modified from those of indirect-developing sea urchins. Changes in cell cleavage patterns accompany the changes in cell fate and axis determination, with for example no production of micromeres by $H$. erythrogramma. In addition, Henry et al (1990) showed that the primary embryo axes were established maternally as well. In indirect-developing sea urchins only the animalvegetal axis is maternal, with the oral-aboral (ventraldorsal) and left-right axes being established later (Duboc et al, 2004, 2005). Changes in cleavage patterns and gastrulation are also evident in evolution of sea star development (Cerra and Byrne, 2004; Byrne, unpublished observations). These features are generally considered to constitute fundamental properties of embryos on the phylum level. Their variation within a single genus shows that such apparent evolutionary stability does not preclude an inability to undergo rapid changes under selection. How such developmental features are governed is still not well understood. However, the mechanisms that execute axial differentiation once development has begun are apparently conserved. The A-V axis in H. erythrogramma uses the same Wnt-8 signal transduction pathway as observed in indirect development (Angerer and Angerer, 2003; Kauffman and Raff, 2003). The $D-V$ and $L-R$ axes are established in indirect developers through the upstream action of the Nodal pathway, and the downstream transcription factor goosecoid (gsc) (Angerer et al, 2001; Duboc et al, 2004, 2005; Flowers et al, 2004). The Nodal signalling system is used twice to generate two distinct axes. First, Nodal is expressed on the ventral side and involved in establishment of the dorsal-ventral axis (Duboc et al, 2004). Nodal then is expressed on the right side and is involved in establishment of the $\mathrm{L}-\mathrm{R}$ axis by repression of left-side differentiation on the right (Duboc et al, 2005). The reactions of $H$. erythrogramma to reagents that affect this pathway suggest that the Nodal signalling pathway likely operates in the execution of both these axes in the direct developer as well, albeit with some important differences (Minsuk and Raff, 2005; Snoke and Raff, unpublished data, 2005). Wilson et al (2005a,b) experimentally showed that gsc expression changes are related to the modifications leading to the non-feeding larval form. Mis/over-expression of gsc mRNA in H. erythrogramma results in an enhanced oral-aboral axis. This result suggests that a reduction in gsc expression in presumptive oral ectoderm may be one of the genic changes underlying the shift in larval morphology. In addition, the appearance of the $\mathrm{L}-\mathrm{R}$ axis in $H$. erythrogramma occurs much earlier in development than it does in the indirect developers, at the end of gastrulation roughly $24 \mathrm{~h}$ after fertilization $v$ s in the feeding larva a few weeks after fertilization (Ferkowicz and Raff, 2001). This heterochronic change involves the same regulatory genes as in the axes of indirect developers, but operating in different developmental stages and in different regulatory environments (Ferkowicz and Raff, 2001; Wilson et al, 2005a, b; Snoke and Raff, unpublished data, 2005).

These results suggest that aspects of axis formation play a role in the evolution of the H. erythrogramma larva. However, more than a single factor is involved. The switch of axis determination to maternal control may allow the very fast development observed in $H$. erythrogramma in pre-forming axial determining systems. The loss of an overt oral face in $H$. erythrogramma, including loss of the larval mouth appears to involve the initial molecular steps in formation of the oral domain coupled with early loss of expression of a major transcription factor, gsc, in that region of the early larva. Finally, formation of the larval L-R axis takes place precociously, and involves gene expression heterochronies that initiate the early second expression domain of the Nodal pathway into early larval development. The consequences of these events taken in concert is to 
drastically speed development, nearly abolish oral side differentiation and morphogenesis, and to advance differentiation and morphogenesis of structures along the $\mathrm{L}-\mathrm{R}$ axis that begin the formation of the juvenile adult rudiment. The adult rudiment is initiated by about $30 \mathrm{~h}$ of development in $H$. erythrogramma, whereas it takes 2-3 weeks in indirect developers. The result is that H. erythrogramma metamorphoses in 3-4 days as opposed to about a month to 6 weeks for indirect-developing species, with significant life history changes. Finally, although there are novel evolutionary features, there also are losses in developmental features and gene expression. Some genes involved in the generation of structures found in the pluteus, such as the arms, gut, or specialized aboral ectoderm are either no longer expressed in the larva, are expressed but in other patterns, or have become pseudogenes (Kissinger et al, 1997; Love and Raff, unpublished data). The conclusion is that several process affecting site, timing and levels of gene action are part of the evolutionary changes leading to rapid larval evolution, including probable roles of large effect genes. The questions of what is being selected on and whether some major changes are neutral results of losses in other genetic pathways remain open. Finally, it has emerged that although the ovoid $H$. erythrogramma larval form is simpler to the eye than the pluteus, the evolutionary transformation has not been primarily one of simplification, but of a suite of novel changes in developmental processes. This situation is formally similar to other cases of apparent evolutionary simplification and reduction, such as in the loss of eyes by cave fish. In that cases, Yamamoto et al $(2003,2004)$ showed that eye loss was the result of changes in hedgehog signaling, apparently under selection for other craniofacial features.

The studies summarized above are all comparative versions of applications of developmental-genetic approaches to functional understanding of the development of embryos and larvae. Our objective is to apply also the synthetic approach to understanding the evolutionary component of developmental evolution to the suit of problems inherent in these evolving developmental systems. It is possible to design studies that start from the evolutionary side of the phenomena being studied. Raff et al (1999) took that approach in making cross species hybrids between $H$. erythrogramma (eggs) and $H$. tuberculata (sperm), which although closely related phylogenetically, are highly distinct in how they develop (Figure 6). In these experiments, a large genetic perturbation is inflicted by mixing two disparate genomes in a single cytoplasm. The surprise was that an ordered ontogeny resulted that yielded a novel developmental pathway, novel larval morphology, including metamorphosis to juvenile sea urchins. Nielsen et al (2000) showed that genes from both genomes were expressed, some in novel patterns. Cross species hybrid crosses are not limited to one direction. Raff et al (1999) did crosses in the reciprocal direction, $H$. tuberculata egg $\times H$. erythrogramma sperm. These hybrids developed to gastrulation, but failed to execute proper axial specification and died as radicalized (no D-V or L-R asymmetry) embryos. The fact that the direction of the cross matters indicates that that it is not only the mix of genomes that matters, but in what egg cytoplasm they are expressed. The failure of these hybrids is one of axis formation, and suggests that in the absence of maternal determination, the hybrid genome cannot initiate axial differentiation. This provides a striking demonstration of the potent role that maternal specification in the $H$. erythrogramma larva.

$H$. erythrogramma $\times H$. tuberculata hybrids developed distinct pluteus features (notably arms, gut, and oral ectoderm) absent in H. erythrogramma. This observation indicated that paternal factors were dominant in hybrid development, and offered practically useful information in the analysis of genes involved in evolution of the direct developer. We focused on the oral ectoderm, which has important roles in the development of the oral-aboral axis and its influence on development of the pluteus skeleton. Critical transcription factors are active there, and we based a search for evolutionary important genes on those (see Wilson et al, $2005 a, b)$. One of the transcription factor genes so isolated was $g S C$, discussed above. In hybrids, $g S C$ is expressed in the morphologically restored oral ectoderm, as in its indirect developer paternal parent, $H$. tuberculata, consistent with the dominance of the paternal pattern. Wilson et al (2005b) have observed that transcription of $H$. tuberculata $g s c$ is differently regulated than $H$. erythrogramma gsc in hybrids and becomes the major gsc transcript.

Other evolutionary questions also have been addressed with cross species hybrids (Raff et al, 2003). In that study, comparisons of $H$. erythrogramma $\times H$. tuberculata hybrids with those made using an evolutionary distant indirect-developing paternal parent made it possible to demonstrate that $H$. erythrogramma evolution has been rapid and punctuational in mode relative to evolution among indirect developers. In addition crosses between $H$. erythrogramma and an independently evolved direct developer from another very distant family indicate that parallel evolution may be operating in the independent evolution of direct developing echinoids.

The use of cross species hybrids has been most used with sea urchins, but is not limited to them. Cross species hybrids between two species of direct-developing starfish produced F1 progeny, which depending on the egg source had an intermediate or maternally determined in arm number (Byrne and Anderson, 1994). This shows that use of hybrids to examine other taxa of echinoderms should be fruitful.

Overall, the evolution of echinoderm larvae presents a rich mix of evolutionary-developmental phenomena that can be studied by use of the diverse and closely related species that have different developmental modes. Tools from comparative embryology, molecular systematics, and developmental genetics allow penetrating studies of mechanisms to be made. Unfortunately, there is a growing probability that the ability of biologists to carry out such studies on evolutionarily important non-laboratory non-model systems may be at risk. The possibilities of continued work depend in the short run on funding agencies being willing to support research on non-model organisms. Further, and more profoundly, research is threatened by the loss of nearshore marine and other environments and their organisms to such human-promoted factors as habitat destruction, climate change and the introduction of invasive species. 


\section{Acknowledgements}

We thank our students and collaborators, Indiana University and the University of Sydney, the US National Science Foundation (RAR), and the Australian Research Council (MB) for making our research possible.

\section{References}

Angerer LM, Angerer RC (2003). Patterning the sea urchin embryo: gene regulatory networks, signaling pathways, and cellular interactions. Curr Top Dev Biol 53: 159-198.

Angerer LM, Oleksyn DW, Levine AM, Li X, Klein WH, Angerer RC (2001). Sea urchin goosecoid function links fate specification along the animal-vegetal and oral-aboral embryonic axes. Development 128: 4393-4404.

Arenas-Mena C, Cameron AR, Davidson EH (2000). Spatial expression of Hox cluster genes in the ontogeny of a sea urchin. Development 127: 4631-4643.

Arendt D, Technau U, Wittbrodt J (2001). Evolution of the bilaterian larval foregut. Nature 409: 81-85.

Byrne M (2006). Life history evolution and the Asterinidae. Int Comp Biol 46: 243-254.

Byrne M, Anderson MJ (1994). Hybridization of sympatric Patiriella species (Echinodermata: Asteroidea) in New South Wales. Evolution 48: 564-576.

Byrne M, Cisternas P, Elia L, Relf B (2005). Engrailed is expressed in larval development and in the radial nervous system of the Patiriella sea stars. Dev Genes Evol 215: 608-617.

Byrne M, Cisternas P, Koop D (2001a). Evolution of larval form in the sea star genus Patiriella. Conservation and change in nervous system development. Dev Growth Differ 43: 459-468.

Byrne M, Emlet R, Cerra A. (2001b). Ciliated band structure in planktotrophic and lecithotrophic larvae of Heliocidaris species (Echinodermata: Echinoidea): conservation and change. Acta Zool 82: 189-199.

Byrne M, Villinski J, Popodi E, Cisternas P, Raff R (1999). Maternal factors and the evolution of developmental mode: Evolution of oogenesis in Heliocidaris erythrogramma. Dev Genes Evol 209: 275-283.

Cameron RA, Rowen L, Nesbitt R, Bloom S, Rast JP, Berney K et al (2006). Unusual gene order and organization of the sea urchin hox cluster. J Exp Zoolog B Mol Dev Evol 306: 45-48.

Cerra A, Byrne M (2004). Evolution of development in the sea star genus Patiriella: clade specific alterations in cleavage. Evol and Dev 6: 105-113.

Chia FS (1974). Classification and the adaptive significance of developmental patterns in marine invertebates. Thalassia jugos 10: 121-130.

Cohn MJ, Tickle C (1999). Developmental basis of limblessness and axial patterning in snakes. Nature 399: 474-479.

Davidson EH, Cameron RA, Ransick A (1998). Specification of cell fate in the sea urchin embryo: summary and some proposed mechanisms. Development 125: 3269-3290.

Duboc V, Rottinger E, Besnardeau L, Lepage T (2004). Nodal and BMP2/4 signaling organizes the oral-aboral axis of the sea urchin embryo. Dev Cell 6: 397-410.

Duboc V, Rottinger E, Lapraz F, Besnardeau L, Lepage T (2005). Left-right asymmetry in the sea urchin embryo is regulated by nodal signaling on the right side. Dev Cell 9: 147-158.

Emlet RB (1995). Larval spicules, cilia, and symmetry as remnants of indirect development in the direct developing sea urchin Heliocidaris erythrogramma. Dev Biol 167: 405-415.

Emlet RB, McEdward LR, Strathmann RR (1987). Echinoderm larval ecology viewed from the egg. In: Jangoux M, Lawrence JM (eds) Echinoderm Studies. Balkema: Rotterdam. Vol. 2, pp 55-136.

Emlet RB, Hoegh-Guldberg O (1997). Effects of egg size on postlarval performance: experimental evidence from a sea urchin. Evolution 51: 141-152.
Ferkowicz MJ, Raff RA (2001). Wnt gene expression in sea urchin development: heterochronies associated with the evolution of developmental mode. Evol Dev 3: 24-33.

Flowers VL, Courteau GR, Poustka AJ, Weng W, Venuti JM (2004). Nodal/activin signaling establishes oral-aboral polarity in the early sea urchin embryo. Dev Dyn 231: 727-740.

Garstang W (1894). Preliminary note on a new theory of the phylogeny of the Chordata. Zool Anz 17: 122-125.

Hart MW, Byrne M, Smith MJ (1997). Molecular phylogenetic analysis of life-history evolution in asterinid starfish. Evolution 51: 1846-1859.

Hart MW, Byrne M, Johnson SL (2003). Cryptic species and modes of development in Patiriella pseudoexigua (Asteroidea: Asterinidae). J Marine Biol Assoc UK 83: 1109-1116.

Hart MW, Johnston SL, Addison JA, Byrne M (2004). Strong character incongruence between life history traits and nucleotides in asterinid sea star phylogeny. Invertebr Biol 123: 343-356.

Haszprunar G, Salvini-Plawen LV, Rieger RM (1995). Larval planktotrophy - a primitive trait for the Bilateria? Acta Zool 76: 141-154.

Henry JJ, Wray GA, Raff RA (1990). The dorsoventral axis is specified prior to first cleavage in the direct developing sea urchin Heliocidaris erythrogramma. Development 110: 875-884.

Hinman VF, Nguyen AT, Cameron RA, Davidson EH (2003). Developmental gene regulatory network architecture across 500 million years of echinoderm evolution. Proc Natl Acad Sci 100: 13356-13361.

Jagersten G (1972). Evolution of the Metazoan Life Cycle. Acad. Press: London.

Jeffery C, Emlet RB (2003). Macroevolutionary consequences of developmental mode in temnopleurid echinoids from the tertiary of southern Australia. Evolution 57: 1031-1048.

Jeffery C, Emlet RB, Littlewood DTJ (2003). Phylogeny and evolution of developmental mode in temnopleurid echinoids. Mol Phylo Evol 28: 99-118.

Kauffman J, Raff RA (2003). Patterning mechanisms in the evolution of derived developmental life histories: the role of Wnt signaling in axis formation of the direct-developing sea urchin Heliocidaris erythrogramma. Dev Genes Evol 213: 612-624.

Kissinger JC, Hahn JH, Raff RA (1997). Rapid evolution in a conserved gene family. Evolution of the actin gene family in the sea urchin genus Heliocidaris and related genera. Mol Biol Evol 14: 654-665.

Lessios HA, Garrido MJ, Kessing BD (2001). Demographic history of Diadema antillarum, a keystone herbivore on Caribbean reefs. Proc Biol Sci 268: 2347-2353.

Love AC, Raff RA (2006). Larval ectoderm, organizational homology, and the origins of evolutionary novelty. I Exp Zoolog B Mol Dev Evol 306: 18-24.

Lowe CJ, Wray GA (1997). Radical alterations in the roles of homeobox genes during echinoderm evolution. Nature 389: 718-721.

McEdward LR, Miner BG (2001). Larval and life-cycle patterns in echinoderms. Can J Zool 79: 1125-1170.

McHugh C, Rouse GW (1998). Life history evolution of marine invertebrates: new views from phylogenetic systematics. Trends Ecol Evol 13: 182-186.

Minsuk SB, Raff RA (2002). Pattern formation in a pentameral animal: induction of early adult rudiment development in sea urchins. Dev Biol 247: 335-350.

Minsuk SB, Raff RA (2005). Co-option of an oralaboral patterning mechanism to control left-right differentiation: the direct-developing sea urchin Heliocidaris erythrogramma is sinistralized, not ventralized, by $\mathrm{NiCl}_{2}$. Evol Dev 7: 289-300.

Mooi R, David B (1998). Evolution within a bizarre phylum: homologies of the first echinoderms. Am Zool 38: 965-974.

Morris VB, Byrne M (2005). Involvement of two Hox genes and Otx in echinoderm body-plan morphogenesis in the sea 
urchin Holopneustes purpurescens. J Exp Zoolog B Mol Dev Evol 304: 456-467.

Nakano H, Hibino T, Oji T, Hara Y, Amemiya S (2003). Larval stages of a living sea lily (stalked crinoid echinoderm). Nature 421: $158-160$.

Nielsen C (1995). Origin and evolution of animal life cycles. Biol Rev 73: 125-155.

Nielsen MG, Wilson KA, Raff EC, Raff RA (2000). Novel gene expression patterns in hybrid embryos between species with different modes of development. Evol Dev 2: 133-144.

Nezlin P, Yushin V (2004). Structure of the nervous system in the tornaria larva of Balanoglossus proterogonius (Hemichordaa: Enteropneusta) and its phylogenetic implications. Zoomorphology 123: 1-13.

Olive PJW (1985). Covariability of reproductive traits in marine invertebrates: implications for the phylogeny of the lower invertebrates.. In: Conway Morris S, George JD, Gibson R, Platt, HM (eds) The Origins and Relationships of Lower Invertebrates. Oxford University Press: Oxford. pp 42-59.

Peterson KJ (2005). Macroevolutionary interplay between planktonic larvae and benthic predators. Geology 33: 929-932.

Raff EC, Popodi EM, Kauffman JS, Sly BJ, Turner FR, Morris VB et al (2003). Regulatory punctuated equilibrium and convergence in the evolution of developmental pathways in directdeveloping sea urchins. Evol Dev 5: 478-493.

Raff EC, Popodi EM, Sly BJ, Turner FR, Villinski JT, Raff RA (1999). A novel ontogenetic pathway in hybrid embryos between species with different modes of development Development 126: 1937-1945.

Raff EC, Villinski JT, Turner FR, Donoghue PCJ, Raff RA (2006). Experimental taphonomy shows the feasibility of fossil embryos. Proc Nat Acad Sci USA 103: 5846-5851.

Raff RA (1992). Direct-developing sea urchins and the evolutionary reorganization of early development. BioEssays 14: 211-218.

Raff RA (1996). The shape of life: genes, development, and the evolution of animal form. The University of Chicago Press, Chicago.

Raff RA, Love AC (2004). Kowalevsky, comparative evolutionary embryology, and the intellectual lineage of evo-devo. J Exp Zoolog B Mol Dev Evol 302: 19-34.

Semon R (1888). Die Entwickelung der Synapta digitata und ihre Bedeutung für die Phylogenie der Echinodermen. Jen Zeitsch F Naturwiss 22: 175-309.

Sly BJ, Hazel JC, Popodi EM, Raff RA (2002). Patterns of gene expression in the developing adult sea urchin central nervous system reveal multiple domains and deep-seated neural pentamery. Evol Dev 4: 189-204.
Sly BJ, Snoke MS, Raff RA (2003). Who came first-larvae or adults? origins of bilaterian metazoan larvae. Int I Dev Biol 47: 623-632.

Smith AB (1997). Echinoderm larvae and phylogeny. Annu Rev Ecol Syst 28: 219-241.

Strathmann RR (1978). The evolution and loss of feeding larval stages of marine invertebrates. Evolution 32: 894-906.

Tagawa K, Satoh N, Humphreys T (2001). Molecular studies of hemichordate development: a key to understanding the evolution of bilateral animals and chordates. Evol Dev 3: $443-454$.

Valentine JW, Collins AG (2000). The significance of moulting in Ecdysozoan evolution. Evol Dev 2: 152-156.

Villinski JT, Villinski JC, Byrne M, Raff RA (2002). Convergent maternal provisioning and life-history evolution in echinoderms. Evol Int J 56: 1764-1775.

Wilson KA, Andrews ME, Turner RF, Raff RA (2005a). Major regulatory factors in the evolution of development: the roles of goosecoid and Msx in the evolution of the directdeveloping sea urchin Heliocidaris erythrogramma. Evol Dev 7: $416-428$

Wilson KA, Andrews ME, Raff RA (2005b). Dissociation of expression patterns of homeodomain transcription factors in the evolution of developmental mode in the sea urchins Heliocidaris tuberculata and H. erythrogramma. Evol Dev 7: 401-415.

Wray GA (1996). Parallel evolution of nonfeeding larvae in echinoids. Syst Biol 45: 308-322.

Wray GA, Raff RA (1989). Evolutionary modification of cell lineage in the direct-developing sea urchin Heliocidaris erythrogramma. Dev Biol 132: 458-470.

Wray GA, Raff RA (1990). Novel origins of lineage founder cells in the direct-developing sea urchin Heliocidaris erythrogramma. Dev Biol 141: 41-54.

Xiao S, Zhang Y, Knoll AH (1998). Three-dimensional preservation of algae and animal embryos in a Neoproterozoic phosphate. Nature 391: 553-558.

Yamamoto Y, Espinasa L, Stock DW, Jeffery WR. (2003). Development and evolution of craniofacial patterning is mediated by eye-dependent and -independent processes in the cavefish Astyanax. Evol Dev 5: 435-446.

Yamamoto Y, Stock DW, Jeffery WR (2004). Hedgehog signaling controls eye degeneration in blind cavefish. Nature 431: 844-847.

Zigler KS, Raff EC, Popodi E, Raff RA, Lessios HA (2003). Adaptive evolution of bindin in the genus Heliocidaris is correlated with the shift to direct development. Evolution 57: 2293-2302. 